\title{
En Route to the Formation of High-Efficiency, Osmium(II)-Based Phosphorescent Materials
}

\author{
Fang-Chi Hsu, Yung-Liang Tung, and Yun Chi* \\ Department of Chemistry, National Tsing Hua University, Hsinchu 300, Taiwan \\ Cheng-Chih Hsu, Yi-Ming Cheng, Mei-Lin Ho, Pi-Tai Chou, ${ }^{*}$ and Shie-Ming Peng \\ Department of Chemistry and Instrumentation Center, National Taiwan University, Taipei 106, \\ Taiwan \\ Arthur J. Carty ${ }^{*}$ \\ Steacie Institute for Molecular Sciences, National Research Council Canada, 100 Sussex Drive, \\ Ottawa, Ontario K1A OR6, Canada \\ Received July 14, 2006
}

\begin{abstract}
Triosmium cluster complexes $\left[\mathrm{Os}_{3}(\mathrm{CO})_{8}(\mathrm{fppz})_{2}\right](2 \mathrm{a})$ and $\left[\mathrm{Os}_{3}(\mathrm{CO})_{8}(\mathrm{fptz})_{2}\right](\mathbf{2 b})$ bearing two 2-pyridyl azolate ligands were synthesized in an attempt to establish the reaction mechanism that gives rise to the blue-emitting phosphorescent complexes $\left[\mathrm{Os}(\mathrm{CO})_{2}(\mathrm{fppz})_{2}\right]\left(\right.$ (1a) and $\left[\mathrm{Os}(\mathrm{CO})_{2}(\mathrm{fptz})_{2}\right](\mathbf{1 b})[(\mathrm{fppz}) \mathrm{H}=3$-(trifluoromethyl)-5-(2-pyridyl)pyrazole; (fptz)H $=3$-(trifluoromethyl)-5-(2-pyridy)triazole]. X-ray structural analysis of $\mathbf{2 b}$ showed an open triangular metal framework incorporating multisite-coordinated 2-pyridyltriazolate ligands. Treatment of 2 with the respective 2-pyridylazolate ligand led to the formation of blue-emitting complex $1 b$, confirming their intermediacy, while the reaction of $2 b$ with phosphine ligand $\mathrm{PPh}_{2} \mathrm{Me}$ afforded two hitherto novel hydride complexes 3 and 4 , for which the reversible interconversion was clearly established at higher temperatures $\left(>180^{\circ} \mathrm{C}\right)$. The single-crystal X-ray diffraction analyses of 3 and $\mathbf{4}$ confirmed their monometallic and isomeric nature, together with the coordination of two phosphine ligands located in the trans-disposition and one $\mathrm{CO}$ and one hydride located opposite to the pyridyl triazolate chelate. Subtle differences in photophysical properties were examined for isomers 3 and $\mathbf{4}$ on the basis of steady state absorption and emission, the relaxation dynamics, and temperature-dependent luminescent studies. The results, in combination with time-dependent density function theory (TDDFT) calculations, provide fundamental insights into the future design and preparation of highly efficient phosphorescent emitters.
\end{abstract}

\section{Introduction}

The third-row transition metal complexes have been extensively utilized for the fabrication of phosphorescent organic light-emitting diodes (OLEDs). ${ }^{1}$ The imposed strong spin-orbit coupling effectively promotes singlet-to-triplet intersystem crossing and enhances the subsequent radiative

\footnotetext{
* To whom correspondence should be addressed. E-mail: ychi@mx.nthu.edu.tw (Y.C.), chop@ntu.edu.tw (P.-T.C.), acarty@pco-bcp.gc.ca (A.J.C.).

(1) (a) Holder, E.; Langeveld, B. M. W.; Schubert, U. S. Adv. Mater 2005, 17, 1109. (b) Yersin, H. Top. Curr. Chem. 2004, 241, 1. (c) Welter, S.; Brunner, K.; Hofstraat, J. W.; De Cola, L. Nature (London) 2003, 421, 54. (d) Sun, Y.; Giebink, N. C.; Kanno, H.; Ma, B.; Thompson, M. E.; Forrest, S. R. Nature 2006, 440, 908. (e) Chou, P.-T.; Chi, Y. Eur. J. Inorg. Chem. 2006, 3319.
}

10188 Inorganic Chemistry, Vol. 45, No. 25, 2006 transition from the triplet state to the ground state. Because an internal phosphorescence quantum efficiency $\left(\eta_{\text {int }}\right)$ of as high as $\sim 100 \%$ could theoretically be achieved, these heavy metal containing emitters, which are capable of harnessing both singlet and triplet excitons, should be superior to their fluorescent counterparts in giving higher device efficiencies. ${ }^{2}$ As a result, research activities are shifting focus from traditional fluorescent dyes to the exploration of heavy transition metal-based phosphorescent emitters, particularly for those metal complexes that possess good thermal and

(2) (a) Adachi, C.; Baldo, M. A.; Thompson, M. E.; Forrest, S. R. J. Appl. Phys. 2001, 90, 5048. (b) Kawamura, Y.; Goushi, K.; Brooks, J.; Brown, J. J.; Sasabe, H.; Adachi, C. Appl. Phys. Lett. 2005, 86, 071104

10.1021/ic061301y CCC: $\$ 33.50$ C 2006 American Chemical Society Published on Web 11/04/2006 
electrochemical stability, better RGB chromaticity, and superior luminescent quantum efficiency upon excitation.

With respect to complexes exhibiting phosphorescence at room temperature, most investigations have been focusing on the $\mathrm{d}^{6}$ and $\mathrm{d}^{8}$ transition metal complexes. ${ }^{3}$ The luminescent platinum(II) $\mathrm{d}^{8}$ metal complexes, however, due to their planar molecular geometry, may induce significant intermolecular interaction in the solid state resulting in difficulties in assessing their photophysical properties and hence the device performance. ${ }^{4}$ On the other hand, both homoleptic and/or heteroleptic coordination architectures of $\mathrm{d}^{6}$ iridium(III) complexes have been extensively studied, showing an elegant interplay between the photophysical properties and the coordinated chromophores. ${ }^{5}$ In particular, octahedral iridium(III) systems with at least two cyclometalating chromophores have shown much more predictable behavior for fabricating light-emitting devices. ${ }^{6}$ As a result, versatile ligand designs can be applied to tune excited-state properties such as emission energy gap, lifetime, and quantum yield.

In yet another approach, to explore the versatility of the octahedral osmium(II) complexes, we have prepared several luminous complexes with formulas $\left[\mathrm{OsI}_{2}(\mathrm{CO})_{2}\right.$ (diimine)] $(\text { diimine }=\text { bipyridine or phenanthroline })^{7}$ and $\left[\mathrm{OsX}(\mathrm{CO})_{3^{-}}\right.$ (chelate)] ( $\mathrm{X}=$ halide or pseudohalide; chelate is, for example, a substituted $\beta$-diketonate ${ }^{8}$ or quinolinolate anion). ${ }^{9}$ Three representative structural drawings are depicted in Chart 1 , for which the accompanying studies have clearly unraveled the nature of the excited states that gave the bright phosphorescence at room temperature. In this paper, we present a comprehensive approach to extend the previously documented reactions involving pyridylazoles (denoted as

(3) (a) Vogler, A.; Kunkely, H. Top. Curr. Chem. 2001, 213, 143. (b) Welter, S.; Salluce, N.; Belser, P.; Groeneveld, M.; De Cola, L. Coord. Chem. Rev. 2005, 249, 1360. (c) Browne, W. R.; O’Boyle, N. M.; McGarvey, J. J.; Vos, J. G. Chem. Soc. Rev. 2005, 34, 641.

(4) (a) Lai, S.-W.; Che, C.-M. Top. Curr. Chem. 2004, 241, 27. (b) Ma, B.; Li, J.; Djurovich, P. I.; Yousufuddin, M.; Bau, R.; Thompson, M. E. J. Am. Chem. Soc. 2005, 127, 28. (c) Lu, W.; Chan, M. C. W.; Zhu, N.; Che, C.-M.; Li, C.; Hui, Z. J. Am. Chem. Soc. 2004, 126, 7639. (d) Kavitha, J.; Chang, S.-Y.; Chi, Y.; Yu, J.-K.; Hu, Y.-H.; Chou, P.-T.; Peng, S.-M.; Lee, G.-H.; Tao, Y.-T.; Chien, C.-H.; Carty, A. J. Adv. Funct. Mater. 2005, 15, 223. (e) Chang, S.-Y.; Kavitha, J.; Li, S.-W.; Hsu, C.-S.; Chi, Y.; Yeh, Y.-S.; Chou, P.-T.; Lee, G.-H.; Carty, A. J.; Tao, Y.-T.; Chien, C.-H. Inorg. Chem. 2006, 45, 137.

(5) (a) Li, J.; Djurovich, P. I.; Alleyne, B. D.; Yousufuddin, M.; Ho, N. N.; Thomas, J. C.; Peters, J. C.; Bau, R.; Thompson, M. E. Inorg. Chem. 2005, 44, 1713. (b) Sajoto, T.; Djurovich, P. I.; Tamayo, A.; Yousufuddin, M.; Bau, R.; Thompson, M. E.; Holmes, R. J.; Forrest, S. R. Inorg. Chem. 2005, 44, 7992. (c) Yang, C.-H.; Li, S.-W.; Chi, Y.; Cheng, Y.-M.; Yeh, Y.-S.; Chou, P.-T.; Lee, G.-H.; Wang, C.-H.; Shu, C.-F. Inorg. Chem. 2005, 44, 7770.

(6) (a) Hwang, F.-M.; Chen, H.-Y.; Chen, P.-S.; Liu, C.-S.; Chi, Y.; Shu, C.-F.; Wu, F.-I.; Chou, P.-T.; Peng, S.-M.; Lee, G.-H. Inorg. Chem. 2005, 44, 1344. (b) You, Y.; Park, S. Y. J. Am. Chem. Soc. 2005, 127, 12438.

(7) Chen, Y.-L.; Lee, S.-W.; Chi, Y.; Hwang, K.-C.; Kumar, S. B.; Hu, Y.-H.; Cheng, Y.-M.; Chou, P.-T.; Peng, S.-M.; Lee, G.-H.; Yeh, S.J.; Chen, C.-T. Inorg. Chem. 2005, 44, 4287.

(8) (a) Chen, Y.-L.; Sinha, C.; Chen, I.-C.; Liu, K.-L.; Chi, Y.; Yu, J.-K.; Chou, P.-T.; Lu, T.-H. Chem. Commun. 2003, 3046. (b) Chen, Y.-L.; Li, S.-W.; Chi, Y.; Cheng, Y.-M.; Pu, S.-C.; Yeh, Y.-S.; Chou, P.-T. ChemPhysChem 2005, 6, 2012.

(9) Cheng, Y.-M.; Yeh, Y.-S.; Ho, M.-L.; Chou, P.-T.; Chen, P.-S.; Chi, Y. Inorg. Chem. 2005, 44, 4594.
Chart 1<smiles></smiles><smiles>[X]C1(C(=O)[O-])OC(=O)C=C(c2ccccc2)O1</smiles><smiles></smiles>

$\mathrm{N} \wedge \mathrm{NH})$ and osmium carbonyl reagent $\mathrm{Os}_{3}(\mathrm{CO})_{12} \cdot{ }^{1 e, 10}$ Attention is paid to several distinctive issues such as possible mechanistic pathways and how to broaden reactivity patterns using newly isolated intermediates.

\section{Experimental Section}

General Information and Materials. All reactions were performed under a nitrogen atmosphere using anhydrous solvents or solvents treated with an appropriate drying reagent. Mass spectra were obtained on a JEOL SX-102A instrument operating in electron impact (EI) mode or fast atom bombardment (FAB) mode. ${ }^{1} \mathrm{H}$ and ${ }^{19} \mathrm{~F}$ NMR spectra were recorded on a Varian Mercury-400 or INOVA-500 instrument. Elemental analyses were conducted at the NSC Regional Instrumentation Center at National Chiao Tung University. The nitrogen chelates, 3-(trifluoromethyl)-5-(2-pyridyl)pyrazole, (fppz)H, and 3-(trifluoromethyl)-5-(2-pyridyl)triazole, (fptz)H, were prepared using methods reported in the literature. ${ }^{11}$

Preparation of 2a. A mixture of $\mathrm{Os}_{3}(\mathrm{CO})_{12}(200 \mathrm{mg}, 0.22 \mathrm{mmol})$ and fppzH (141 mg, $0.66 \mathrm{mmol})$ in $25 \mathrm{~mL}$ of anhydrous diethylene glycol monoethyl ether (DGME) was heated at $180{ }^{\circ} \mathrm{C}$ for $12 \mathrm{~h}$. After being cooled to room temperature, the solvent was removed under vacuum and the residue purified using silica gel column chromatography, eluting with a mixture of ethyl acetate (EA) and hexane $(1: 1)$. A yellow crystalline sample of $\left[\mathrm{Os}_{3}(\mathrm{CO})_{8}(\mathrm{fppz})_{2}\right]$ was obtained from $\mathrm{CH}_{2} \mathrm{Cl}_{2}$ and methanol at room temperature; yield $72 \%$ (193 mg, $0.16 \mathrm{mmol})$.

Spectral data for 2a: MS (FAB, $\left.{ }^{192} \mathrm{Os}\right) \mathrm{m} / \mathrm{z}, 1224\left(\mathrm{M}^{+}\right)$; IR $\left(\mathrm{C}_{6} \mathrm{H}_{12}\right) v(\mathrm{CO}), 2079$ (s), 2012 (vs), 1996 (vs), 1970 (w), 1944 (s) $\mathrm{cm}^{-1} ;{ }^{1} \mathrm{H}$ NMR $\left(500 \mathrm{MHz}\right.$, acetone- $\left.d_{6}, 294 \mathrm{~K}\right) \delta 9.25\left(\mathrm{~d}, 1 \mathrm{H}, J_{\mathrm{HH}}\right.$ $=5.0 \mathrm{~Hz}), 8.16\left(\mathrm{td}, 1 \mathrm{H}, J_{\mathrm{HH}}=8.0,1.0 \mathrm{~Hz}\right), 8.04\left(\mathrm{~d}, 1 \mathrm{H}, J_{\mathrm{HH}}=\right.$ $8.0 \mathrm{~Hz}), 7.64\left(\mathrm{ddd}, 1 \mathrm{H}, J_{\mathrm{HH}}=6.3,6.0,1.5 \mathrm{~Hz}\right), 7.14(\mathrm{~s}, 1 \mathrm{H}) ;{ }^{19} \mathrm{~F}$ NMR (470 MHz, acetone- $\left.d_{6}\right) \delta-57.5(\mathrm{~s})$. Anal. Calcd for $\mathrm{C}_{26} \mathrm{H}_{10} \mathrm{~F}_{6} \mathrm{~N}_{6} \mathrm{O}_{8} \mathrm{Os}_{3}$ : C, 25.62; $\mathrm{N}, 6.98 ; \mathrm{H}, 0.83$. Found: C, 25.87; N, 6.84; H, 0.81.

Preparation of $\mathbf{2 b}$. Similar to the procedure described for $\mathbf{2 a}$, this product was prepared using $\mathrm{Os}_{3}(\mathrm{CO})_{12}(200 \mathrm{mg}, 0.22 \mathrm{mmol})$ and fptzH $(142 \mathrm{mg}, 0.66 \mathrm{mmol})$. Yellow crystals of $\left[\mathrm{Os}_{3}(\mathrm{CO})_{8^{-}}\right.$ (fptz) $)_{2}$ were obtained by recrystallization from a mixture of $\mathrm{CH}_{2}-$ $\mathrm{Cl}_{2}$ and methanol; yield $60 \%$ (161 $\left.\mathrm{mg}, 0.13 \mathrm{mmol}\right)$.

Spectral data for $\mathbf{2 b}$ : MS (FAB, $\left.{ }^{192} \mathrm{Os}\right) \mathrm{m} / \mathrm{z} 1226\left(\mathrm{M}^{+}\right)$; IR $\left(\mathrm{C}_{6} \mathrm{H}_{12}\right) v(\mathrm{CO}), 2083(\mathrm{w}), 2015$ (vs), $2000(\mathrm{~s}), 1976(\mathrm{w}), 1949 \mathrm{~cm}^{-1}$; ${ }^{1} \mathrm{H}$ NMR $\left(500 \mathrm{MHz}\right.$, acetone- $\left.d_{6}, 294 \mathrm{~K}\right) \delta 9.39\left(\mathrm{~d}, 1 \mathrm{H}, J_{\mathrm{HH}}=5.5\right.$ $\mathrm{Hz}), 8.32\left(\mathrm{td}, 1 \mathrm{H}, J_{\mathrm{HH}}=8.0,1.5 \mathrm{~Hz}\right), 8.11\left(\mathrm{~d}, 1 \mathrm{H}, J_{\mathrm{HH}}=8.0 \mathrm{~Hz}\right)$, $7.88\left(\mathrm{ddd}, 1 \mathrm{H}, J_{\mathrm{HH}}=6.3,5.5,1.5 \mathrm{~Hz}\right) ;{ }^{19} \mathrm{~F} \mathrm{NMR}(470 \mathrm{MHz}$,

(10) (a) Wu, P.-C.; Yu, J.-K.; Song, Y.-H.; Chi, Y.; Chou, P.-T.; Peng, S.-M.; Lee, G.-H. Organometallics 2003, 22, 4938. (b) Yu, J.-K.; Hu, Y.-H.; Cheng, Y.-M.; Chou, P.-T.; Peng, S.-M.; Lee, G.-H.; Carty, A. J.; Tung, Y.-L.; Lee, S.-W.; Chi, Y.; Liu, C.-S. Chem--Eur. J. 2004, 10, 6255 .

(11) (a) Yu, W.-S.; Cheng, C.-C.; Cheng, Y.-M.; Wu, P.-C.; Song, Y.-H.; Chi, Y.; Chou, P.-T. J. Am. Chem. Soc. 2003, 125, 10800. (b) Cheng, C.-C.; Yu, W.-S.; Chou, P.-T.; Peng, S.-M.; Lee, G.-H.; Wu, P.-C.; Song, Y.-H.; Chi, Y. Chem. Commun. 2003, 2628. (c) Klingele, M. H.; Brooker, S. Coord. Chem. Rev. 2003, 241, 119. 
Hsu et al.

Table 1. Crystal Data and Structure Refinement Parameters for Complexes 2b, 3, and 4

\begin{tabular}{|c|c|c|c|}
\hline param & $2 \mathbf{b}$ & 3 & 4 \\
\hline empirical formula & $\mathrm{C}_{24} \mathrm{H}_{8} \mathrm{~F}_{6} \mathrm{~N}_{8} \mathrm{O}_{8} \mathrm{Os}_{3}$ & $\mathrm{C}_{35} \mathrm{H}_{31} \mathrm{~F}_{3} \mathrm{~N}_{4} \mathrm{OO} \mathrm{OP}_{2}$ & $\mathrm{C}_{35} \mathrm{H}_{31} \mathrm{~F}_{3} \mathrm{~N}_{4} \mathrm{OOSP}_{2} \cdot 1 / 2 \mathrm{CH}_{2} \mathrm{Cl}_{2}$ \\
\hline fw & 1220.98 & 832.78 & 875.24 \\
\hline temp $(\mathrm{K})$ & $295(2)$ & $295(2)$ & $150(1)$ \\
\hline cryst system & monoclinic & monoclinic & monoclinic \\
\hline space group & $P 2_{1} / c$ & $P 2_{1} / c$ & $P 2_{1} / n$ \\
\hline$a(\AA)$ & $16.9045(8)$ & $11.1450(5)$ & $10.2530(4)$ \\
\hline$b(\AA)$ & $13.6895(7)$ & $32.2482(14)$ & $15.8852(6)$ \\
\hline$c(\AA)$ & $12.7028(6)$ & $9.5374(4)$ & $20.9409(8)$ \\
\hline$\beta$ (deg) & $93.774(1)$ & $90.0610(10)$ & $90.366(1)$ \\
\hline$V\left(\AA^{3}\right), Z$ & $2933.2(2), 4$ & $3427.8(3), 4$ & $3410.6(2), 4$ \\
\hline$d($ calcd $)\left(\mathrm{Mg} / \mathrm{m}^{3}\right)$ & 2.765 & 1.614 & 1.705 \\
\hline abs coeff $\left(\mathrm{mm}^{-1}\right)$ & 13.065 & 3.863 & 3.963 \\
\hline$F(000)$ & 2216 & 1640 & 1724 \\
\hline cryst size $\left(\mathrm{mm}^{3}\right)$ & $0.28 \times 0.20 \times 0.20$ & $0.23 \times 0.14 \times 0.06$ & $0.30 \times 0.15 \times 0.10$ \\
\hline reflens collcd & 28854 & 27933 & 33813 \\
\hline indepdt reflcns & $6738[\mathrm{R}$ (int) $=0.0503]$ & $6045[\mathrm{R}$ (int) $=0.0631]$ & $7854[\mathrm{R}(\mathrm{int})=0.0593]$ \\
\hline max and min transm & 0.1798 and 0.1209 & 0.8013 and 0.4702 & 0.6927 and 0.3827 \\
\hline data/restraints/params & $6738 / 0 / 452$ & $6045 / 0 / 448$ & $7845 / 1 / 514$ \\
\hline goodness-of-fit on $F^{2}$ & 1.027 & 1.189 & 1.020 \\
\hline final $\mathrm{R}$ indices $[I>2 \sigma(I)]$ & $\mathrm{R}_{1}=0.0329, \mathrm{wR}_{2}=0.0679$ & $\mathrm{R}_{1}=0.0562, \mathrm{wR}_{2}=0.1035$ & $\mathrm{R}_{1}=0.0364, \mathrm{wR}_{2}=0.0773$ \\
\hline $\mathrm{R}$ indices (all data) & $\mathrm{R}_{1}=0.0425, \mathrm{wR}_{2}=0.0716$ & $\mathrm{R}_{1}=0.0703, \mathrm{wR}_{2}=0.1083$ & $\mathrm{R}_{1}=0.0491, \mathrm{wR}_{2}=0.0823$ \\
\hline largest diff peak and hole $\left(\mathrm{e} \AA^{-3}\right)$ & 1.363 and -1.075 & 1.378 and -2.394 & 1.574 and -1.781 \\
\hline
\end{tabular}

acetone- $\left.d_{6}\right) \delta-61.8$ (s). Anal. Calcd for $\mathrm{C}_{24} \mathrm{H}_{8} \mathrm{~F}_{6} \mathrm{~N}_{8} \mathrm{O}_{8} \mathrm{Os}_{3}$ : C, 23.61; N, 9.18; H, 0.66. Found: C, 23.75; N, 9.27; H, 1.01.

Reaction of $2 \mathrm{a}$ with fppzH and $2 \mathrm{~b}$ with fptzH. A mixture of 2a (100 mg, $0.08 \mathrm{mmol})$ and fppzH (78.7 mg, $0.36 \mathrm{mmol})$ in 10 $\mathrm{mL}$ of DGME was heated at $190{ }^{\circ} \mathrm{C}$ for $24 \mathrm{~h}$. Solvent was removed under vacuum, and the residue was separated using silica gel column chromatography (ethyl acetate), giving $64 \mathrm{mg}$ of recovered 2a $(0.052 \mathrm{mmol}, 64 \%)$ together with blue-emitting 1a $\left[\mathrm{Os}(\mathrm{CO})_{2}(\mathrm{fppz})_{2}\right]$ (51 mg, $0.075 \mathrm{mmol}, 31 \%$ ). Similarly, complex $\mathbf{2 b}$ reacted with fptzH to afford $\mathbf{1 b}$ and unreacted $\mathbf{2 b}$ in $35 \%$ and $60 \%$ of yields, respectively.

Reaction of $\mathbf{2 b}$ with $\mathbf{P P h}_{\mathbf{2}} \mathbf{M e}$. A mixture of $\mathbf{2 b}$ (200 mg, 0.16 mmol) and $\mathrm{PPh}_{2} \mathrm{Me}(183 \mu \mathrm{L}, 0.98 \mathrm{mmol})$ in $25 \mathrm{~mL}$ of DGME was heated at $180{ }^{\circ} \mathrm{C}$ for $12 \mathrm{~h}$. After being cooled to room temperature, the solvent was removed and the residue was separated using silica gel column chromatography (1:1 ethyl acetate/hexane), giving a blue-emitting complex 3 (75 mg, $0.09 \mathrm{mmol}, 55 \%$ ) together with a green-emitting complex 4 (14 mg, 0.016 mmol, 10\%) according to the sequence of their elution. Single crystals of $\mathbf{3}$ and $\mathbf{4}$ were obtained by recrystallization from a mixture of EA/hexane and $\mathrm{CH}_{2}-$ $\mathrm{Cl}_{2}$ /hexane, respectively.

Spectral data for 3: MS (FAB, $\left.{ }^{192} \mathrm{Os}\right) \mathrm{m} / \mathrm{z} 834\left(\mathrm{M}^{+}\right), 634\left(\mathrm{M}^{+}\right.$ - $\left.\mathrm{PPh}_{2} \mathrm{Me}\right) ; \mathrm{IR}\left(\mathrm{CH}_{2} \mathrm{Cl}_{2}\right) v(\mathrm{Os}-\mathrm{H}), 2053(\mathrm{w}), v(\mathrm{CO}), 1912$ (vs) $\mathrm{cm}^{-1}$; ${ }^{1} \mathrm{H}$ NMR $\left(500 \mathrm{MHz}\right.$, acetone- $\left.d_{6}, 294 \mathrm{~K}\right) \delta 8.14\left(\mathrm{~d}, 1 \mathrm{H}, J_{\mathrm{HH}}\right.$ $=5.0 \mathrm{~Hz}), 7.62\left(\mathrm{t}, 1 \mathrm{H}, J_{\mathrm{HH}}=7.5 \mathrm{~Hz}\right), 7.43\left(\mathrm{~d}, 1 \mathrm{H}, J_{\mathrm{HH}}=7.5 \mathrm{~Hz}\right)$, 7.39-7.35 (m, 4H), 7.32-7.29 (m, 2H), 7.25-7.19 (m, 14H), 6.85 $\left(\mathrm{t}, 1 \mathrm{H}, J_{\mathrm{HH}}=6.5 \mathrm{~Hz}\right), 1.71\left(\mathrm{t}, 6 \mathrm{H}, J_{\mathrm{HP}}=3.0 \mathrm{~Hz}, \mathrm{CH}_{3}\right),-12.77(\mathrm{t}$, $\left.1 \mathrm{H}, J_{\mathrm{HP}}=18.5 \mathrm{~Hz}\right) ;{ }^{31} \mathrm{P}$ NMR $\left(202 \mathrm{MHz}\right.$, acetone- $\left.d_{6}\right) \delta 0.73(\mathrm{~s})$; ${ }^{19} \mathrm{~F}$ NMR $\left(470 \mathrm{MHz}\right.$, acetone- $\left.d_{6}\right) \delta-62.7(\mathrm{~s})$. Anal. Calcd for $\mathrm{C}_{35} \mathrm{H}_{31} \mathrm{~F}_{3} \mathrm{~N}_{4} \mathrm{OO} \mathrm{O}_{2}$ : C, 50.48; N, 6.73; H, 3.75. Found: C, 50.52; N, 6.79; H, 3.81.

Spectral data for 4: MS (FAB, $\left.{ }^{192} \mathrm{Os}\right) \mathrm{m} / \mathrm{z} 834\left(\mathrm{M}^{+}\right), 634\left(\mathrm{M}^{+}\right.$ - $\left.\mathrm{PPh}_{2} \mathrm{Me}\right)$; IR $\left(\mathrm{CH}_{2} \mathrm{Cl}_{2}\right) v(\mathrm{Os}-\mathrm{H}), 2016$ (w), v(CO), 1937 (vs) $\mathrm{cm}^{-1} ;{ }^{1} \mathrm{H}$ NMR $\left(500 \mathrm{MHz}\right.$, acetone- $\left.d_{6}, 294 \mathrm{~K}\right) \delta 7.94\left(\mathrm{~d}, 1 \mathrm{H}, J_{\mathrm{HH}}\right.$ $=5.5 \mathrm{~Hz}), 7.49\left(\mathrm{~d}, 1 \mathrm{H}, J_{\mathrm{HH}}=7.5 \mathrm{~Hz}\right), 7.42-7.40(\mathrm{~m}, 4 \mathrm{H}), 7.33-$ $7.28(\mathrm{~m}, 3 \mathrm{H}), 7.23-7.20(\mathrm{~m}, 4 \mathrm{H}), 7.19-7.17(\mathrm{~m}, 2 \mathrm{H}), 7.13-7.08$ $(\mathrm{m}, 8 \mathrm{H}) 6.53\left(\mathrm{ddd}, 1 \mathrm{H}, J_{\mathrm{HH}}=6.3,5.5,1.5 \mathrm{~Hz}\right), 2.06\left(\mathrm{t}, 6 \mathrm{H}, J_{\mathrm{HP}}=\right.$ $3.5 \mathrm{~Hz}, \mathrm{Me}),-12.28\left(\mathrm{t}, 1 \mathrm{H}, J_{\mathrm{HP}}=18.0 \mathrm{~Hz}\right) ;{ }^{31} \mathrm{P} \mathrm{NMR}(202 \mathrm{MHz}$, acetone- $\left.d_{6}\right) \delta-0.57(\mathrm{~s}) ;{ }^{19} \mathrm{~F}$ NMR $\left(470 \mathrm{MHz}\right.$, acetone- $\left.d_{6}\right) \delta-62.4$ (s). Anal. Calcd for $\mathrm{C}_{35} \mathrm{H}_{31} \mathrm{~F}_{3} \mathrm{~N}_{4} \mathrm{OOSP}_{2}$ : C, 50.48; N, 6.73; H, 3.75. Found: C, 50.47; N, 6.78; H, 3.96 .
Isomerization of 3. A DGME solution of $\mathbf{3}(20 \mathrm{mg}, 0.024 \mathrm{mmol})$ was heated at $180{ }^{\circ} \mathrm{C}$ for $24 \mathrm{~h}$. After being cooled to room temperature, the solvent was removed under vacuum and the residue was separated using silica gel column chromatography (1:1 ethyl acetate/hexane), giving $10 \mathrm{mg}$ of recovered $3(0.012 \mathrm{mmol}, 50 \%)$ and $5.0 \mathrm{mg}$ of $4(0.006 \mathrm{mmol}, 25 \%)$.

Isomerization of 4. A DGME solution of $4(20 \mathrm{mg}, 0.024 \mathrm{mmol})$ was heated at $180{ }^{\circ} \mathrm{C}$ for $24 \mathrm{~h}$. After being cooled to room temperature, the solvent was removed under vacuum and the solid residue was separated using silica gel column chromatography (1:1 ethyl acetate/hexane), giving $4.0 \mathrm{mg}$ of $\mathbf{3}(0.005 \mathrm{mmol}, 20 \%)$ and $9.6 \mathrm{mg}$ of unreacted $4(0.012 \mathrm{mmol}, 48 \%)$. Note that from a thermodynamic viewpoint, the same ratio should be expected for both forward $(\mathbf{3} \rightarrow \mathbf{4})$ and reverse reactions $(\mathbf{4} \rightarrow \mathbf{3})$. Unfortunately, reversibility is not sufficient due to certain sample decomposition during heating. Accordingly, only qualitative results were reported here.

X-ray Structural Determination. Single-crystal X-ray diffraction data were recorded on a Bruker SMART CCD diffractometer using $\lambda(\mathrm{Mo} \mathrm{K} \alpha)$ radiation $(\lambda=0.71073 \AA)$. The data collection was executed using the SMART program. Cell refinement and data reduction were made with the SAINT program. The structure was determined using the SHELXTL/PC program and refined using fullmatrix least squares. All non-hydrogen atoms were refined anisotropically, whereas hydrogen atoms were placed at the calculated positions and included in the final stage of refinements with fixed positional parameters. The crystallographic refinement parameters of complexes $\mathbf{2 b}, \mathbf{3}$, and $\mathbf{4}$ are summarized in Table 1 , while the selective bond distances and angles of these complexes are listed in Tables $2-4$, respectively.

Spectral Measurement. Steady-state absorption and emission spectra were recorded with a Hitachi (U-3310) spectrophotometer and an Edinburgh (FS920) fluorometer, respectively. Quinine sulfate with an emission yield of $\Phi \sim 0.55\left(\lambda_{\max } \sim 460 \mathrm{~nm}\right)$ in $0.1 \mathrm{M}$ $\mathrm{H}_{2} \mathrm{SO}_{4}$ served as a standard to calculate the emission quantum yield. ${ }^{12}$ Lifetime studies were performed with an Edinburgh FL 900 photon-counting system with a hydrogen-filled/or a nitrogen lamp as the excitation source. Data were analyzed using the nonlinear least-squares procedure in combination with an iterative

(12) Demas, J. N.; Crosby, G. A. J. Phys. Chem. 1971, 75, 991. 
convolution method. The emission decays were analyzed by the sum of exponential functions, which allows partial removal of the instrument time broadening and consequently renders a temporal resolution of $\sim 200$ ps.

Computational Methodology. Time-dependent DFT calculations based on the geometry taken from the X-ray analyses of complexes $\mathbf{3}$ and $\mathbf{4}$ were carried out using a hybrid B3LYP method, ${ }^{13}$ while a double- $\zeta$ quality basis set consisting of Hay and Wadt's effective core potentials (LANL2DZ) ${ }^{14}$ was employed for osmium atoms; a $6-31 \mathrm{G}\left(\mathrm{d}^{\prime}, \mathrm{p}^{\prime}\right)$ basis set was employed for the $\mathrm{H}$, $\mathrm{C}, \mathrm{N}, \mathrm{F}, \mathrm{P}$, and $\mathrm{O}$ atoms. A relativistic effective core potential (ECP) replaced the inner core electrons of Os(II), leaving the outer core $\left(5 s^{2} 5 p^{6}\right)$ electrons and the $5 d^{6}$ valence electrons. Typically, the lowest triplet and singlet roots of the nonhermitian eigenvalue equations were obtained to determine the vertical excitation energies. Oscillator strengths were deduced from the dipole transition matrix elements (for singlet states only). The excitedstate TDDFT calculations were carried out using Gaussian03. ${ }^{15}$

\section{Results}

Synthesis and Characterization. It has been reported that the simplest and most straightforward synthetic route to the blue-emitting osmium(II) complexes 1a,b involves the direct treatment of $\mathrm{Os}_{3}(\mathrm{CO})_{12}$ with at least 6 equiv of pyridylazole chelate (denoted as $\mathrm{N} \wedge \mathrm{NH}$ ) in a high boiling alcohol solvent DGME (Scheme 1). ${ }^{10}$ The reaction possibly proceeds through a multistep process, involving the prior formation of mononuclear intermediates such as $\mathrm{Os}(\mathrm{CO})_{x}, 4 \leq x \leq 2$, followed by addition of $\mathrm{N} \wedge \mathrm{NH}$ ligands, $\mathrm{CO}$ dissociation, and the removal of an activated hydrogen atom on the $\mathrm{N} \wedge \mathrm{N}$ chelate. However, due to the stronger Os-Os bonding interaction, the simultaneous cleavage of all three Os-Os bonds of $\mathrm{Os}_{3^{-}}$ $(\mathrm{CO})_{12}$ in forming the intermediate $\mathrm{Os}(\mathrm{CO})_{x}$ would require excess thermal energy and become exceedingly difficult. This leads us to believe that the dissociation of the Os-Os bonds should occur in a stepwise manner during the reaction. Such a proposed mechanism prompted us to conduct the reaction employing a reduced amount of the $\mathrm{N} \wedge \mathrm{NH}$ ligand in an attempt to isolate the possible reaction intermediates.

A remarkable contrast was immediately observed upon changing the molar ratio of $\mathrm{Os}_{3}(\mathrm{CO})_{12}$ and pyridyl pyrazolate

(13) (a) Becke, A. D. J. Chem. Phys. 1993, 98, 5648. (b) Lee, C.; Yang, W.; Parr, R. G. Phys. Rev. B 1988, 37, 785.

(14) (a) Dunning, T. H.; Hay, P. J. In Modern Theoretical Chemistry; Schaefer, H. F., III, Ed.; Plenum Press: New York, 1976; Vol. 3, p 11. (b) Hay, P. J.; Wadt, W. R. J. Chem. Phys. 1985, 82, 270. (c) Wadt, W. R.; Hay, P. J. J. Chem. Phys. 1985, 82, 284. (d) Hay, P. J.; Wadt, W. R. J. Chem. Phys. 1985, 82, 299.

(15) Frisch, M. J.; Trucks, G. W.; Schlegel, H. B.; Scuseria, G. E.; Robb, M. A.; Cheeseman, J. R.; Montgomery, J. A., Jr.; Vreven, T.; Kudin, K. N.; Burant, J. C.; Millam, J. M.; Iyengar, S. S.; Tomasi, J.; Barone, V.; Mennucci, B.; Cossi, M.; Scalmani, G.; Rega, N.; Petersson, G. A.; Nakatsuji, H.; Hada, M.; Ehara, M.; Toyota, K.; Fukuda, R.; Hasegawa, J.; Ishida, M.; Nakajima, T.; Honda, Y.; Kitao, O.; Nakai, H.; Klene, M.; Li, X.; Knox, J. E.; Hratchian, H. P.; Cross, J. B.; Bakken, V.; Adamo, C.; Jaramillo, J.; Gomperts, R.; Stratmann, R. E.; Yazyev, O.; Austin, A. J.; Cammi, R.; Pomelli, C.; Ochterski, J. W.; Ayala, P. Y.; Morokuma, K.; Voth, G. A.; Salvador, P.; Dannenberg, J. J.; Zakrzewski, V. G.; Dapprich, S.; Daniels, A. D.; Strain, M. C.; Farkas, O.; Malick, D. K.; Rabuck, A. D.; Raghavachari, K.; Foresman, J. B.; Ortiz, J. V.; Cui, Q.; Baboul, A. G.; Clifford, S.; Cioslowski, J.; Stefanov, B. B.; Liu, G.; Liashenko, A.; Piskorz, P.; Komaromi, I.; Martin, R. L.; Fox, D. J.; Keith, T.; Al-Laham, M. A.; Peng, C. Y.; Nanayakkara, A.; Challacombe, M.; Gill, P. M. W.; Johnson, B.; Chen, W.; Wong, M. W.; Gonzalez, C.; Pople, J. A. Gaussian 03, revision C.02; Gaussian, Inc.: Wallingford, CT, 2004.

\section{Scheme 1}

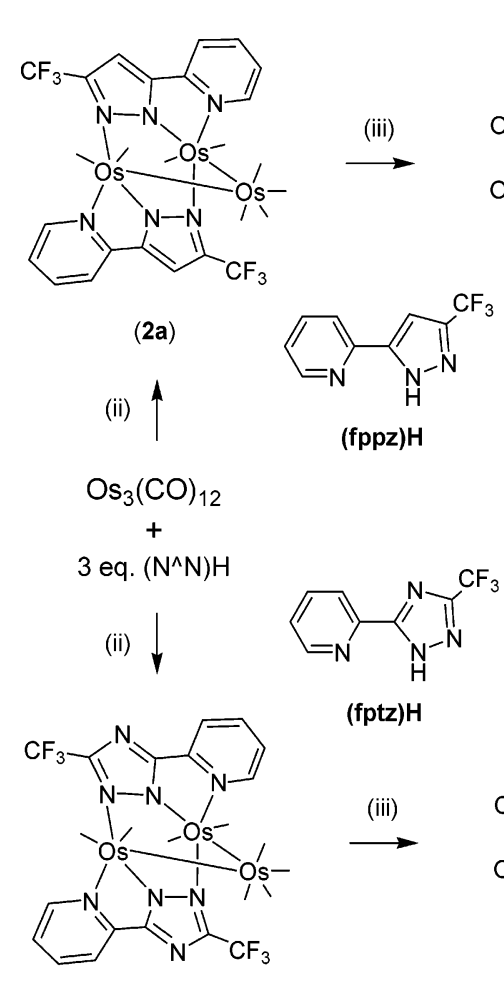

(2b)

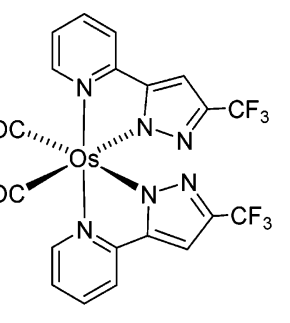

(1a)

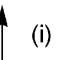

$\mathrm{Os}_{3}(\mathrm{CO})_{12}$

6 eq. $\left(\mathrm{N}^{\wedge} \mathrm{N}\right) \mathrm{H}$

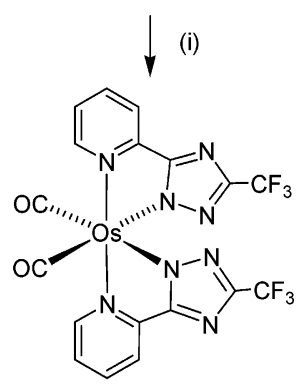

(1b)

fppzH from $1: 6$ to $1: 3$, leading to the formation of a distinctive yellow complex $\left[\mathrm{Os}_{3}(\mathrm{CO})_{8}(\mathrm{fppz})_{2}\right](\mathbf{2 a})$ in $72 \%$ yield, together with only trace amounts of the original blueemitting product $\left[\mathrm{Os}(\mathrm{CO})_{2}(\mathrm{fppz})_{2}\right]$ (1a). A similar transformation was observed when $\mathrm{Os}_{3}(\mathrm{CO})_{12}$ was treated with 3 equiv of pyridyltriazole fptzH under similar conditions, giving the analogous cluster complex $\left[\mathrm{Os}_{3}(\mathrm{CO})_{8}(\mathrm{fptz})_{2}\right](\mathbf{2 b})$ in a slightly lower yield (60\%). The FAB mass spectrometry of the azolate complexes $\mathbf{2} \mathbf{a}, \mathbf{b}$ revealed the molecular ion $\left(\mathrm{M}^{+}\right)$signals at $\mathrm{m} / \mathrm{z}=1224$ and 1226, providing clear evidence for the incorporation of two fppz (or fptz) ligands into the triosmium framework, together with the retention of eight ancillary carbonyl ligands. In good agreement with this prediction, the IR spectra of both $\mathbf{2 a}$, $\mathbf{b}$ in $\mathrm{CH}_{2} \mathrm{Cl}_{2}$ showed five sharp $v(\mathrm{CO})$ absorptions in the range $2083-1944 \mathrm{~cm}^{-1}$, confirming the multimetallic cluster nature, while the simplified ${ }^{1} \mathrm{H}$ and ${ }^{19} \mathrm{~F}$ NMR spectral pattern revealed the existence of two magnetically equivalent $\mathrm{N} \wedge \mathrm{N}$ chelates due to the inherent $C_{2}$ symmetry of the complexes.

An X-ray diffraction study of triazolate complex $\mathbf{2 b}$ was then carried out to further confirm the structural identities of these molecules. As presented in Figure 1, three osmium atoms are linked in an open triangular geometry with OsOs distances being 2.8401(4) and 2.8440(4) Å, which deviate only slightly from the average value in parent compound $\mathrm{Os}_{3}(\mathrm{CO})_{12}(2.877 \AA) .{ }^{16}$ The through-space contact between the nonbonded osmium atoms is notably longer, 3.771(1) $\AA$, which is even longer than that $(3.078 \AA)$ observed in the open triangular alkoxide cluster complex $\left[\mathrm{Os}_{3}(\mathrm{CO})_{10}(\mu\right.$ $\mathrm{OMe})_{2}$ ], for which the nonbonding interaction is consistent

(16) Churchill, M. R.; DeBoer, B. G. Inorg. Chem. 1977, 16, 878. 
Hsu et al.

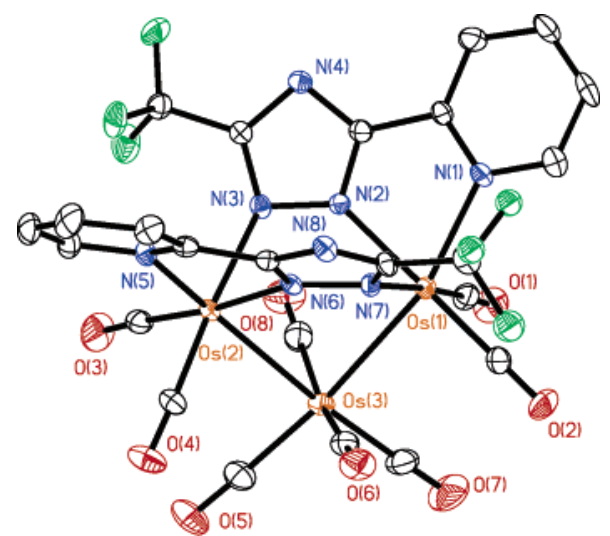

Figure 1. ORTEP diagram of $\mathbf{2 b}$ with thermal ellipsoids shown at $30 \%$ probability level.

Scheme 2

(2b)

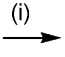

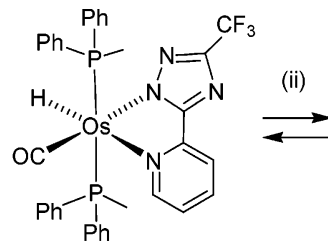

(3)

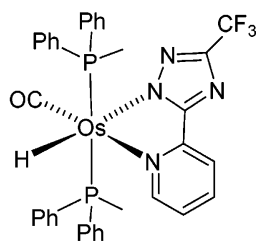

(4) with a simple electron counting using the 18 -electron rule. ${ }^{17}$ Moreover, all osmium atoms in $\mathbf{2 b}$ displayed a pseudooctahedral coordination. For the central osmium atom, the geometry is clearly defined by four carbonyl ligands and two cis-oriented Os-Os bonds. For the other osmium atoms, each is coordinated by three facially arranged nitrogen atoms deriving from the triazolate chelates. These $\mathrm{Os}-\mathrm{N}$ distances varied from 2.097 to $2.222 \AA$, with the distances to the neutral pyridyl fragments $(\mathrm{Os}(1)-\mathrm{N}(1)=2.204(5) \AA$ and Os $(2)-\mathrm{N}(5)=2.222(5) \AA$ ) being significant longer than those to the anionic triazolate ligand distances $(2.097-2.172$ $\AA$ ). The overall bonding arrangement associated with these multisite coordinated triazolate ligands is closely related to that found in several first-row iron(III) and copper(II) pyridyl azolate complexes. ${ }^{18}$

After confirming the structure of $\mathbf{2}$, we then proceeded to investigate the chemical properties associated with these new cluster complexes. For the reactions between $\mathbf{2 a}$ and fppzH (or $\mathbf{2 b}$ and fptzH), the main products are the previously reported blue-emitting complexes $\mathbf{1 a}$ (or $\mathbf{1 b}$ ) obtained by direct treatment of $\mathrm{Os}_{3}(\mathrm{CO})_{12}$ with the pyridylazoles (Scheme 1)..$^{10}$ These reactions obviously confirmed the roles of $\mathbf{2 a}, \mathbf{b}$ as possible reaction intermediates.

To further explore the versatile synthetic aspect of $\mathbf{2}$, we also investigated the reactions of $\mathbf{2 b}$ with excess $\mathrm{PPh}_{2} \mathrm{Me}$ in DGME solution (Scheme 2). A simple chromatographic

(17) (a) Braga, D.; Sabatino, P.; Johnson, B. F. G.; Lewis, J.; Massey, A. J. Organomet. Chem. 1992, 436, 73. (b) Allen, V. E.; Mason, R.; Hitchcock, P. B. J. Organomet. Chem. 1977, 140, 297.

(18) (a) Slangen, P. M.; van Koningsbruggen, P. J.; Haasnoot, J. G.; Jansen, J.; Gorter, S.; Reedijk, J.; Kooijman, H.; Smeets, W. J. J.; Spek, A. L. Inorg. Chim. Acta 1993, 212, 289. (b) Jones, P. L.; Jeffery, J. C.; McCleverty, J. A.; Ward, M. D. Polyhedron 1997, 16, 1567. (c) Jeffery, J. C.; Jones, P. L.; Mann, K. L. V.; Psillakis, E.; McCleverty, J. A.; Ward, M. D.; White, C. M. Chem. Commun. 1997, 175

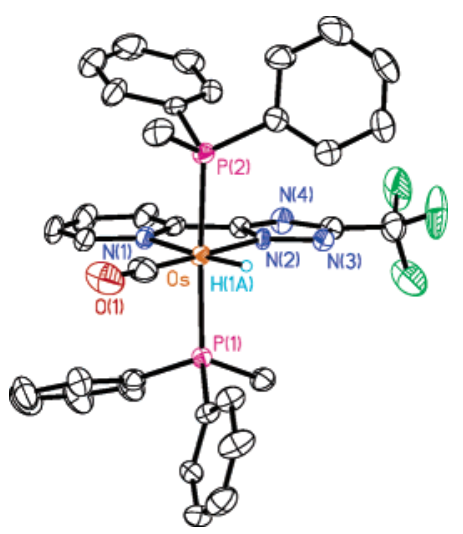

Figure 2. ORTEP diagram of $\mathbf{3}$ with thermal ellipsoids shown at $30 \%$ probability level.

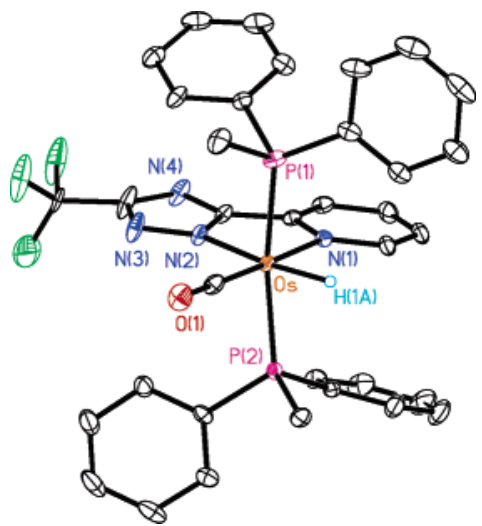

Figure 3. ORTEP diagram of $\mathbf{4}$ with thermal ellipsoids shown at $30 \%$ probability level.

separation yielded a blue-emitting complex $\mathbf{3}$ and a greenemitting complex 4 in 55\% and 10\% of the isolated yields, respectively. Spectroscopic investigation revealed that complexes 3 and $\mathbf{4}$ were isomeric, as both possess one pyridyltriazolate chelate, one carbonyl and one terminal hydride ligand attached to the osmium(II) center, and two symmetrically arranged $\mathrm{PPh}_{2} \mathrm{Me}$ ligands (vide infra). The source of hydride has not been confirmed, but the DGME solvent could plausibly be the major supplier. The hydride spectral pattern is consistent with this formulation in that it is coupled to two identical and strongly coupled phosphorus nuclei and thus appears as a triplet in the ${ }^{1} \mathrm{H}$ NMR spectra. Furthermore, heating a DGME solution of either 3 or 4 to $>180{ }^{\circ} \mathrm{C}$ afforded a mixture of both complexes (see Experimental Section for the details), suggesting that these hydride complexes are interconvertible at the higher temperature. The reaction of 2a with $\mathrm{PPh}_{2} \mathrm{Me}$ in DGME solution displays an essentially identical result, namely the formation of two hydride isomers, and thus is not discussed here to avoid redundancy.

Complexes $\mathbf{3}$ and $\mathbf{4}$ were further characterized through crystal structural analysis. Figures 2 and 3 reveal their molecular structures, while the metric parameters are depicted in Tables 3 and 4 for complexes $\mathbf{3}$ and $\mathbf{4}$, respectively. The $\mathrm{PPh}_{2} \mathrm{Me}$ ligands in both complexes adopt a trans-configuration, with $\mathrm{Os}-\mathrm{P}$ distances in the range of $2.325-2.352$ $\AA$, which are comparable to that of the red-emitting Os(II) 
Table 2. Selected Bond Lengths $(\AA)$ and Angles (deg) for Complex 2b

\begin{tabular}{lllr}
\hline Os(1)-Os(3) & $2.8401(4)$ & Os(2)-Os(3) & $2.8440(4)$ \\
Os(1) $\cdots$ Os(2) & $3.771(1)$ & Os(1)-N(1) & $2.204(5)$ \\
Os(1)-N(2) & $2.121(5)$ & Os(2)-N(3) & $2.167(5)$ \\
Os(2)-N(5) & $2.222(5)$ & Os(2)-N(6) & $2.097(5)$ \\
Os(1)-N(7) & $2.172(5)$ & & \\
& & & \\
Os(1)-Os(3)-Os(2) & $83.127(10)$ & $\mathrm{N}(2)-\mathrm{Os}(1)-\mathrm{N}(1)$ & $73.58(19)$ \\
$\mathrm{N}(5)-\operatorname{Os}(2)-\mathrm{N}(6)$ & $73.28(19)$ & &
\end{tabular}

Table 3. Selected Bond Lengths ( $\AA$ ) and Angles (deg) for Complex 3

\begin{tabular}{lcll}
\hline Os-N(1) & $2.190(6)$ & Os-N(2) & $2.127(6)$ \\
Os-P(1) & $2.351(2)$ & Os-P(2) & $2.352(2)$ \\
Os-H(1A) & $1.41(7)$ & Os-C(1) & $1.824(10)$ \\
$\mathrm{C}(1)-\mathrm{O}(1)$ & $1.176(11)$ & & \\
& & & \\
$\mathrm{P}(1)-\mathrm{Os}-\mathrm{P}(2)$ & $177.52(7)$ & $\mathrm{N}(1)-\mathrm{Os}-\mathrm{N}(2)$ & $74.9(2)$ \\
$\mathrm{N}(2)-\mathrm{Os}-\mathrm{C}(1)$ & $176.1(3)$ & &
\end{tabular}

Table 4. Selected Bond Lengths ( $($ ) and Angles (deg) for Complex 4

\begin{tabular}{lclc}
\hline Os-N(1) & $2.166(3)$ & Os-N(2) & $2.136(3)$ \\
$\mathrm{Os}-\mathrm{P}(1)$ & $2.3410(13)$ & $\mathrm{Os}-\mathrm{P}(2)$ & $2.3247(12)$ \\
$\mathrm{Os}-\mathrm{H}(1 \mathrm{~A})$ & $1.60(5)$ & $\mathrm{Os}-\mathrm{C}(1)$ & $1.835(5)$ \\
$\mathrm{C}(1)-\mathrm{O}(1)$ & $1.159(6)$ & & \\
& & & \\
$\mathrm{P}(1)-\mathrm{Os}-\mathrm{P}(2)$ & $168.98(4)$ & $\mathrm{N}(1)-\mathrm{Os}-\mathrm{N}(2)$ & $74.99(14)$ \\
$\mathrm{N}(2)-\mathrm{Os}-\mathrm{C}(1)$ & $101.64(17)$ & &
\end{tabular}

complex $\left[\mathrm{Os}(\mathrm{fppz})_{2}\left(\mathrm{PPh}_{2} \mathrm{Me}\right)_{2}\right](2.362 \AA)^{19}$ and the corresponding porphinato $(2.369 \AA)$ and the benzotriazolato analogues $(2.353 \AA){ }^{20,21}$ Moreover, it is notable that the pyridyl group in $\mathbf{3}$ is located trans to the strong $\sigma$-donating hydride ligand. This unique feature has caused a lengthening of the Os- $\mathrm{N}(\mathrm{py})$ distance in $3(\mathrm{Os}-\mathrm{N}(1)=2.190 \AA)$, compared with that of its geometric isomer $4(\mathrm{Os}-\mathrm{N}(1)=$ $2.166 \AA$ ), for which the pyridyl unit is located trans to the $\pi$-accepting CO ligand. The reverse alternation of the Os $-\mathrm{N}$ bond distances is also detected for the triazolate segments, indicating that the hydride is a better trans-directing ligand compared with the $\pi$-accepting CO ligand within this class of complexes. Finally, the structures of $\mathbf{3}$ and $\mathbf{4}$ are akin to that of the ionic Os(II) complexes trans-[Os(diimine $)\left(\mathrm{PPh}_{3}\right)_{2^{-}}$ $(\mathrm{CO}) \mathrm{H}]^{+}$, which are prepared by ligand substitution employing neutral diimine ligand and mer- $\left[\mathrm{Os}\left(\mathrm{PPh}_{3}\right)_{3}(\mathrm{CO})(\mathrm{H}) \mathrm{Cl}\right] .{ }^{22}$

Photophysical Properties. In addition to the geometrical isomerism, significant differences in photophysical properties were observed between 3 and $\mathbf{4}$. Figure 4 illustrates the absorption and emission spectra of complexes $\mathbf{3}$ and $\mathbf{4}$ in cyclohexane, while Table 5 summarizes some important photophysical parameters. In general, both $\mathbf{3}$ and $\mathbf{4}$ possess nearly identical, fully allowed absorption bands in the UV region of $<350 \mathrm{~nm}$, for which $\epsilon$ values at the absorption maxima were calculated to be $>10^{4} \mathrm{M}^{-1} \mathrm{~cm}^{-1}$ and can thus be attributed to the local ${ }^{1} \pi \pi^{*}$ transition of the pyridine, triazolate fragment, and/or phosphine ligands. This assignment is confirmed by observation of two ${ }^{1} \pi \pi^{*}$ bands for

(19) Tung, Y.-L.; Wu, P.-C.; Liu, C.-S.; Chi, Y.; Yu, J.-K.; Hu, Y.-H.; Chou, P.-T.; Peng, S.-M.; Lee, G.-H.; Tao, Y.; Carty, A. J.; Shu, C.F.; Wu, F.-I. Organometallics 2004, 23, 3745.

(20) Xie, J.; Huang, J.-S.; Zhu, N.; Zhou, Z.-Y.; Che, C.-M. Chem.-Eur. J. 2005, 11, 2405.

(21) Olby, B. G.; Robinson, S. D.; Hursthouse, M. B.; Short, R. L. J. Chem. Soc., Dalton Trans. 1990, 621.

(22) Sullivan, B. P.; Caspar, J. V.; Meyer, T. J. Organometallics 1984, 3 , 1241. the parent fptz anion $\left(\lambda_{\max } \sim 256\right.$ and $\left.285 \mathrm{~nm}\right)$ as well as those of the related fppz ligand reported in the literature. ${ }^{10 a}$ As for the lower lying states, the broad, structureless band at $>350 \mathrm{~nm}$ for $\mathbf{3}$ and $\mathbf{4}$ can be tentatively assigned to a mainly, metal-ligand charge transfer (MLCT) transition in the singlet manifold. Differences in these lower lying transitions were promptly observed between $\mathbf{3}$ and $\mathbf{4}$, in which the absorption peak of $373 \mathrm{~nm}$ in $\mathbf{3}$ is notably redshifted to $\sim 406 \mathrm{~nm}$ in $\mathbf{4}$. Since the only difference between 3 and $\mathbf{4}$ is the relative orientation of $\mathrm{CO}$ (or $\mathrm{H}$ ) with respect to the 2-pyridyltriazolate moiety, a possible explanation might lie in the strong $\pi$-accepting properties of $\mathrm{CO}$ vs the superior $\sigma$-donating behavior of the hydride ligand. On this basis, the net effect of $\pi$-acceptance from CO not only causes an electron deficiency in the $\mathrm{Os}(\mathrm{II}) \mathrm{d}_{\pi}$ orbital but also influences the moiety at the trans position, i.e., the deficiency of electron density at the triazolate and pyridyl moieties for 3 and 4, respectively. It has been well established that, for the pyridyl triazolate chelate, the lowest intraligand transition normally incorporates the promotion of the $\pi$ electron from the triazolate to the pyridyl moiety. ${ }^{23}$ Accordingly, for the case of $\mathbf{3}$, such a CO trans-effect should result in a decrease of the triazolate energy level and hence an increase of the triazolate $\rightarrow$ pyridyl energy gap. In similar fashion, an opposite effect is thus expected for $\mathbf{4}$ in that the $\pi$ electron deficiency in the pyridyl moiety should lead to a decrease of the triazolate $\rightarrow$ pyridyl energy gap, consistent with the corresponding absorption spectral differences between $\mathbf{3}$ and 4.

Further confirmation of the above viewpoint is provided by the theoretical approach. On the basis of TDDFT calculations, Figure 5 depicts the features of the highest occupied (HOMO) and the lowest unoccupied (LUMO) frontier orbitals of $\mathbf{3}$ and $\mathbf{4}$ mainly involved in the lower lying transition, while the descriptions and the energy gaps of each transition are listed in Table 6. In addition, the HOMO-1 orbital of $\mathbf{3}$ which plays a key role in the lowest triplet excited state (vide infra) is also shown here. As for a direct comparison of the spectral data, the lowest singlet transitions of 337 and $408 \mathrm{~nm}$ calculated for $\mathbf{3}$ and $\mathbf{4}$, respectively, are in good agreement with those $(\mathbf{3}, 373 \mathrm{~nm} ; \mathbf{4}, 410 \mathrm{~nm})$ obtained from the absorption spectra. The deviation of the current theoretical approach from the experimental results is not unexpected, given the underestimation of the mixing among the high-density low-lying states or the less-extensive basis set used for the Os(II) atom. Careful frontier orbital analyses conclude that the lowest singlet excitation mainly incorporates the HOMO $\rightarrow$ LUMO transition, in which the electron densities of the HOMO for $\mathbf{3}$ are mainly located at the $\operatorname{Os}\left(\mathrm{d}_{\pi}\right)$ orbital, while it is simultaneously distributed over both the $\operatorname{Os}\left(\mathrm{d}_{\pi}\right)$ orbital and the triazolate moiety for $\mathbf{4}$. For the LUMO, the electron densities are mainly distributed on the pyridyl moiety of the fptz ligand in both complexes, indicating that the corresponding $S_{0} \rightarrow S_{1}$ transition for $\mathbf{3}$ and $\mathbf{4}$ involves a pure MLCT and an ILCT/MLCT mixture,

(23) Chen, H.-Y.; Chi, Y.; Liu, C.-S.; Yu, J.-K.; Cheng, Y.-M.; Chen, K.S.; Chou, P.-T.; Peng, S.-M.; Lee, G.-H.; Carty, A. J.; Yeh, S.-J.; Chen, C.-T. Adv. Funct. Mater. 2005, 15, 567. 
Hsu et al.

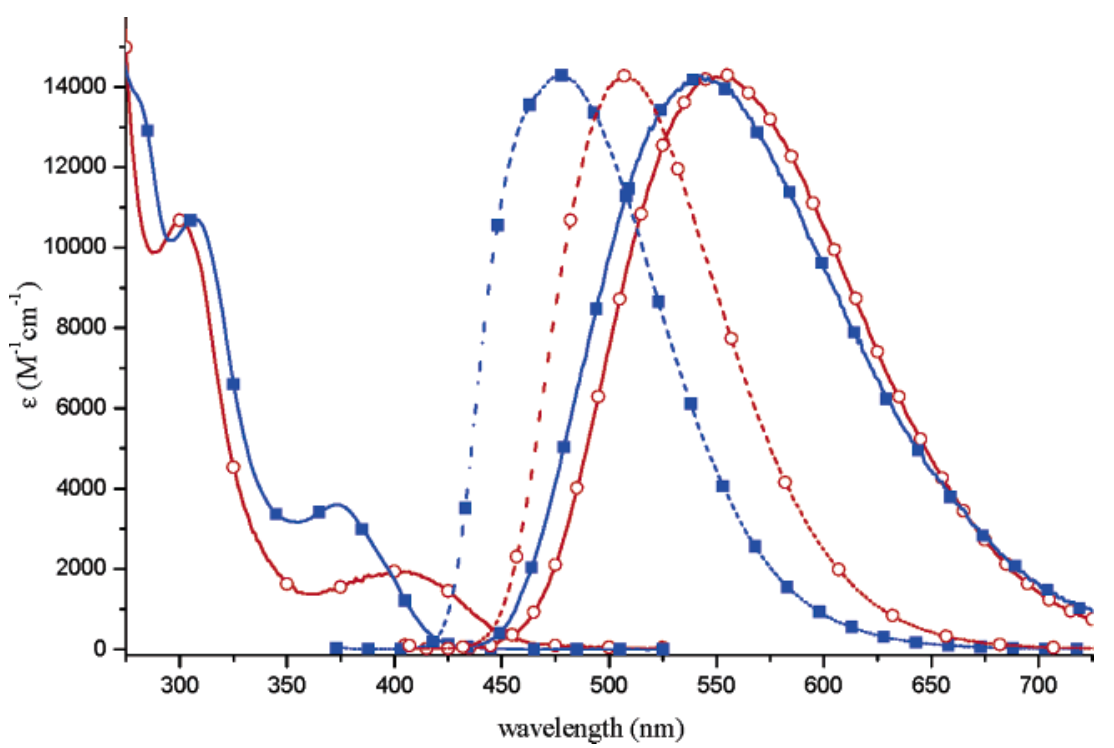

Figure 4. UV-vis absorption and normalized emission spectra of $3(\square)$ and $4(O)$ in cyclohexane at room temperature, as well as the emission spectra of solid crystal (dashed line). Note that the emission spectra have been normalized.

Table 5. Photophysical Properties of $\mathbf{3}$ and $\mathbf{4}$ in Degassed Cyclohexane at Room Temperature

\begin{tabular}{cccccc}
\hline compd & abs: $\lambda_{\max }(\mathrm{nm})\left[10^{-3} \epsilon\left(\mathrm{M}^{-} 1 \cdot \mathrm{cm}^{-} 1\right)\right]$ & $\lambda_{\mathrm{em}}(\mathrm{nm})$ & $\tau_{\mathrm{em}}(\mu \mathrm{s})$ & $\Phi$ & $10^{-4} k_{\mathrm{r}}\left(\mathrm{s}^{-1}\right)$ \\
\hline $\mathbf{3}$ & $273[14], 307[11], 373[3.6]$ & $543[475]^{a}(500)^{b}$ & 0.4 & 0.01 & 2.5 \\
$\mathbf{4}$ & $265[27], 303[10], 406[2.0]$ & $553[510]^{a}(515)^{b}$ & 6.7 & 0.38 & 5.6
\end{tabular}

${ }^{a}$ Data in brackets were measured as thin solid film $(298 \mathrm{~K}) .{ }^{b}$ Data in parentheses were measured in $77 \mathrm{~K}$ methylcyclohexane.

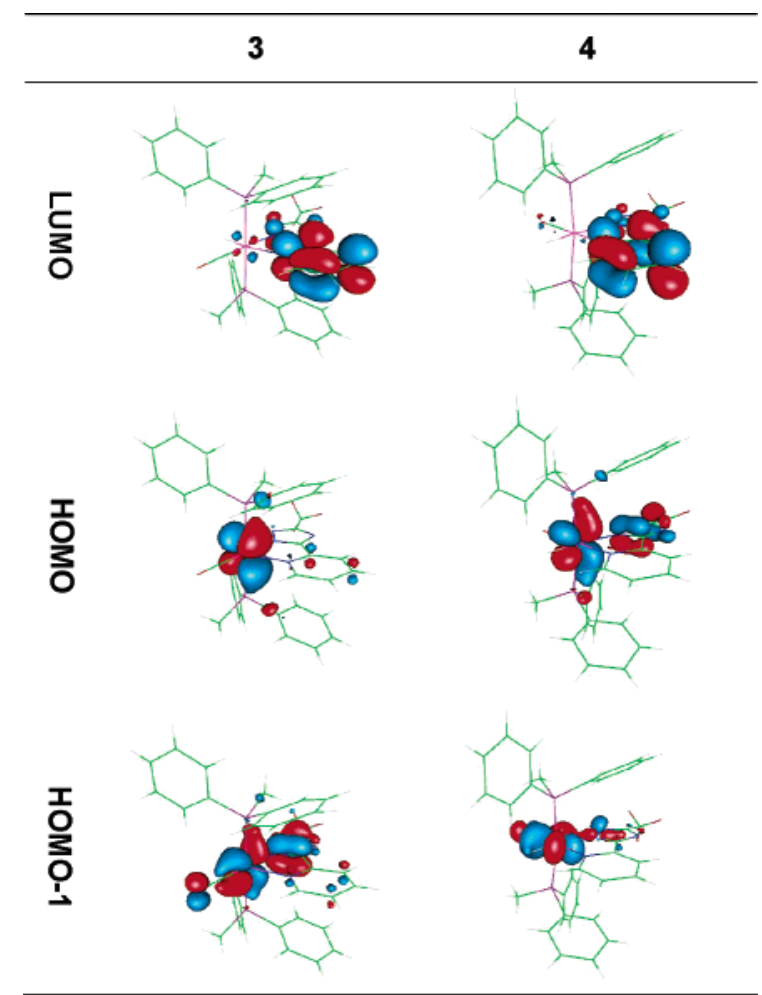

Figure 5. HOMO and LUMO of complexes 3 and 4. Note that that the lowest lying state in both singlet and triplet manifolds is dominated by the HOMO $\rightarrow$ LUMO transition.

respectively. As for $\mathbf{3}$, the lack of contribution from triazolate to the HOMO can be rationalized simply by its decrease in energy due to the aforementioned trans-effect raised by the $\pi$-accepting nature of CO ligand. Thus, the TDDFT approach is promising and the proposed $\pi$-accepting influence of its
trans-CO moiety should play a key role in explaining the subtle differences in the $\mathrm{S}_{0}-\mathrm{S}_{1}$ absorption properties between 3 and 4.

Despite the significant difference in the lower lying absorption spectral feature, as depicted in Figure 4, the corresponding emission profiles of $\mathbf{3}$ and $\mathbf{4}$, with peak wavelengths at 543 and $553 \mathrm{~nm}$, respectively, in cyclohexane are strikingly similar, except that the quantum efficiency in 3 (0.01 in degassed cyclohexane) is much lower than that in 4 (0.38). Both $543 \mathrm{~nm}(3)$ and $553 \mathrm{~nm}(4)$ emission bands are strongly quenched by oxygen. For example, under oxygen-free conditions, the quantum efficiency of the $\sim 553$ $\mathrm{nm}$ emission for $\mathbf{4}$ in cyclohexane was measured to be as high as 0.38 , with a lifetime of $6.7 \mu$ s (see Table 5). Upon aeration, the corresponding quantum efficiency and lifetime were drastically reduced to $2 \times 10^{-3}$ and $220 \mathrm{~ns}$, respectively. For both 543 (3) and $553 \mathrm{~nm}$ (4) emission, the plot of decay rate versus $\mathrm{O}_{2}$ concentration reveals a straight line (not shown here) and the $\mathrm{O}_{2}$ quenching rate constant was deduced to be $2.1 \times 10^{9}$ (for 3) and $2.3 \times 10^{9}$ (for 4) $\mathrm{M}^{-1} \mathrm{~s}^{-1}$, which is nearly $1 / 9$ of the diffusion-controlled rate, consistent with a quenching mechanism that incorporates collision-induced triplet (3 or 4)-triplet $\left(\mathrm{O}_{2}\right)$ energy transfer. This result, in combination with the steady-state resolved large $0-0$ splitting (defined as the peak-to-peak frequency between absorption and emission) of as large as $\sim 8300$ and $6500 \mathrm{~cm}^{-1}$ for 3 and 4, respectively and the lack of vibronic progression feature, leads us to conclude that both $543 \mathrm{~nm}(3)$ and 553 $n m$ (4) emission originates mainly from a $T_{1} \rightarrow S_{0}$ phosphorescence, in which $T_{1}$ possesses a mixing ${ }^{3} \pi \pi^{*}$ and ${ }^{3}{ }_{-}$ MLCT in character. The lack of fluorescence surely guar- 
Table 6. Calculated Energy Levels of the $T_{1}$ and $S_{1}$ Transitions for Complexes 3 and 4

\begin{tabular}{|c|c|c|c|c|c|c|}
\hline compd & type & $\lambda(\mathrm{nm})$ & $E(\mathrm{eV})$ & transitions & main character ${ }^{a}$ & $f$ \\
\hline \multirow[t]{2}{*}{3} & $\mathrm{~T}_{1}$ & 385.3 & 3.22 & HOMO $\rightarrow$ LUMO $(65 \%) ;$ HOMO- $1 \rightarrow$ LUMO $(23 \%)$ & MLCT, 53.8\%; ILCT, 5.3\%; LLCT, $1.8 \%$ & 0 \\
\hline & $\mathrm{S}_{1}$ & 337.3 & 3.68 & $\mathrm{HOMO} \rightarrow$ LUMO $(81 \%)$ & MLCT, 57.9\%; ILCT, $\approx 0 \%$ & 0.0209 \\
\hline \multirow[t]{2}{*}{4} & $\mathrm{~T}_{1}$ & 449.6 & 2.76 & HOMO $\rightarrow$ LUMO $(97 \%)$ & MLCT, $50.3 \%$; ILCT, $13.7 \%$ & 0 \\
\hline & $\mathrm{S}_{1}$ & 408.1 & 3.04 & $\mathrm{HOMO} \rightarrow$ LUMO $(94 \%)$ & MLCT, $48.8 \%$; ILCT, $13.2 \%$ & 0.0249 \\
\hline
\end{tabular}

${ }^{a}$ The main character of each transition is calculated according to the specific $\mathrm{S}_{1}$ or $\mathrm{T}_{1}$ excited states, while MLCT, ILCT, and LLCT represents Os( $\left.\mathrm{d}_{\pi}\right)$ $\rightarrow \pi^{*}$ (pyridyl), $\pi$ (triazolate) $\rightarrow \pi^{*}$ (pyridyl), and $\mathrm{CO} \rightarrow \pi^{*}$ (pyridyl) transitions, respectively.

antees an ultrafast osmium-enhanced $\mathrm{S}_{1} \rightarrow \mathrm{T}_{1}$ intersystem crossing rate.

A further intriguing photophysical property lies in the observation of a significant hypsochromic shift of phosphorescence for both $3(475 \mathrm{~nm})$ and $4(510 \mathrm{~nm})$ in the solid state in comparison to that in cyclohexane (see Figure 4). The possibility that the blue shift originates from crystal packing effects is very unlikely due to the octahedral geometry anchored by two bulky $\mathrm{PPh}_{2} \mathrm{Me}$ auxiliary ligands at the trans dispositions. Further ideas regarding a rational mechanism are elaborated in the Discussion. It is however worthy of note here that the solid-state emission peak wavelength of $3(475 \mathrm{~nm})$ is located very close to the best blue-emitting iridium (III) complexes documented in the literature. ${ }^{5,24}$

\section{Discussion}

As shown in Table 6, the TDDFT approach also predicts an appreciably large difference in $\mathrm{S}_{0}-\mathrm{T}_{1}$ energy gap (vibronic $0-0$ onset) between $3(385 \mathrm{~nm})$ and $4(450 \mathrm{~nm})$. Knowing that the absorption spectroscopy and/or TDDFT approach are strictly based on a vertical excitation, the notable difference in the absorption feature with a similar phosphorescence profile between $\mathbf{3}$ and $\mathbf{4}$ must imply a great variation in the photophysical properties for $\mathbf{3}$ (or $\mathbf{4}$ ) prior to the emission. One possible explanation lies in a large dipolar change for 3 in the $T_{1}$ state (with respect to its ground state), such that a prominent solvent relaxation takes place, resulting in a significant positive phosphorescence solvatochromism, ${ }^{25}$ of which the emission peak wavelength is coincidentally similar to that of $\mathbf{4}$. However, the nonpolar cyclohexane used to obtain the results shown in Figure 4 casts serious doubt on this proposed mechanism. Moreover, the negligible solvent-polarity dependent emission for $\mathbf{3}$ from cyclohexane $(543 \mathrm{~nm})$ to $\mathrm{CH}_{3} \mathrm{CN}(552 \mathrm{~nm})$ further undermines this proposal. In yet another approach, a photolysis experiment has been performed for both $\mathbf{3}$ and $\mathbf{4}$ in cyclohexane upon $355 \mathrm{~nm}$ excitation (3rd harmonic of Nd:YAG, $10 \mathrm{~mJ} / \mathrm{cm}^{2}$, $10 \mathrm{~Hz}$ ). Within a photolysis period of $30 \mathrm{~min}$, negligible spectral changes were observed in both absorption and emission for complexes $\mathbf{3}$ and $\mathbf{4}$, eliminating the possibility

(24) (a) Coppo, P.; Plummer, E. A.; De Cola, L. Chem. Commun. 2004, 1774. (b) Yeh, S.-J.; Wu, W.-C.; Chen, C.-T.; Song, Y.-H.; Chi, Y.; Ho, M.-H.; Hsu, S.-F.; Chen, C.-H. Adv. Mater. 2005, 17, 285. (c) Mak, C. S. K.; Hayer, A.; Pascu, S. I.; Watkins, S. E.; Holmes, A. B.; Koehler, A.; Friend, R. H. Chem. Commun. 2005, 4708. (d) Lyu, Y.Y.; Byun, Y.; Kwon, O.; Han, E.; Jeon, W. S.; Das, R. R.; Char, K. J. Phys. Chem. B 2006, 110, 10303.

(25) (a) Farley, S. J.; Rochester, D. L.; Thompson, A. L.; Howard, J. A. K.; Williams, J. A. G. Inorg. Chem. 2005, 44, 9690. (b) Yu, J.-K.; Cheng, Y.-M.; Hu, Y.-H.; Chou, P.-T.; Chen, Y.-L.; Lee, S.-W.; Chi, Y. J. Phys. Chem. B. 2004, 108, 19908. of photoisomerization, i.e., interconversion, between $\mathbf{3}$ and 4 in the excited state.

Knowing that the above spectral differences rely on absorption and emission in singlet and triplet manifolds, respectively, one plausible rationalization may lie in the fact that there exists an intrinsic difference in the orbital configuration between singlet $\left(\mathrm{S}_{1}\right)$ and triplet $\left(\mathrm{T}_{1}\right)$ states. As such, theoretical approaches may provide a possible clue to unravel the enigma. As depicted in Figure 5 and Table 6, in sharp contrast to a pure MLCT excited-state incorporating the $\mathrm{HOMO} \rightarrow$ LUMO transition for the $\mathrm{S}_{1}$ state, the respective $\mathrm{T}_{1}$ state in 3 mainly consists of mixed HOMO $\rightarrow$ LUMO and HOMO- $1 \rightarrow$ LUMO transitions, in which the $\mathrm{T}_{1}$ state is composed of an appreciable portion $(1.8 \%)$ of $\mathrm{CO} \rightarrow \pi^{*}$ (pyridyl) of LLCT character (see Figure 5 and Table 6). After the photoexcitation, the deficiency of the $\mathrm{CO} \pi$-character greatly reduces the $\pi$-accepting strength, hence weakening the Os-CO bonding strength, possibly resulting in a significant distortion of the potential energy surface with respect to that of the ground state. Accordingly, a large Stokes shift (peak-to-peak) is expected between absorption (either $\mathrm{S}_{0} \rightarrow \mathrm{S}_{1}$ or $\mathrm{S}_{0} \rightarrow \mathrm{T}_{1}$ (if resolvable)) and phosphorescence for $\mathbf{3}$. In sharp contrast, for $\mathbf{4}$, as depicted in Table 6 and Figure 5 , the $\mathrm{T}_{1}$ state mainly involves the HOMO $\rightarrow$ LUMO transition, in which the contribution of $\mathrm{CO} \rightarrow \pi^{*}$ (pyridyl) LLCT is essentially zero, resulting in a mirror image between absorption $\left(\mathrm{S}_{0} \rightarrow \mathrm{T}_{1}\right)$ and phosphorescence.

On the basis of the above arguments, one might expect a weakening of $\mathrm{Os}-\mathrm{CO}$ bond, for which the potential energy surface must be much shallower than that of the ground state. The great distortion between these two potential energy surfaces may facilitate surface crossing and hence the radiationless transition. ${ }^{10,26}$ Accordingly, the corresponding motions associated with the $\mathrm{Os}-\mathrm{CO}$ bond may serve as a good deactivation mode and channel into the radiationless pathways. One strong piece of spectral evidence for this proposed mechanism lies in the $\sim 40$-fold difference of phosphorescence intensity between $\mathbf{3}\left(\Phi_{\mathrm{p}} \sim 0.01\right)$ and $\mathbf{4}\left(\Phi_{\mathrm{p}}\right.$ $\sim 0.38$ ) in room-temperature cyclohexane solution, despite the similar magnitude of the radiative decay rates (see Table 5). We further carried out a temperature-dependent study of 3 in methylcyclohexane. As depicted in Figure 6, upon decrease of the temperature from 310 to $\sim 176 \mathrm{~K}$, the phosphorescence intensity increased $\sim 10$-fold accompanied by an increase of the observed decay time $\left(\tau_{\mathrm{obs}}=1 / k_{\mathrm{obs}}\right)$ from 0.4 to $6.5 \mu \mathrm{s}$. Assuming that the observed decay rate obtained at $77 \mathrm{~K}$ (vide infra) is equivalent to $k_{\mathrm{r}}+k_{\mathrm{nr}}$, where

(26) Li, S.-W.; Cheng, Y.-M.; Yeh, Y.-S.; Hsu, C.-C.; Chou, P.-T.; Peng, S.-M.; Lee, G.-H.; Tung, Y.-L.; Wu, P.-C.; Chi, Y.; Wu, F.-I.; Shu, C.-F. Chem.-Eur. J. 2005, 11, 6347. 
Hsu et al.

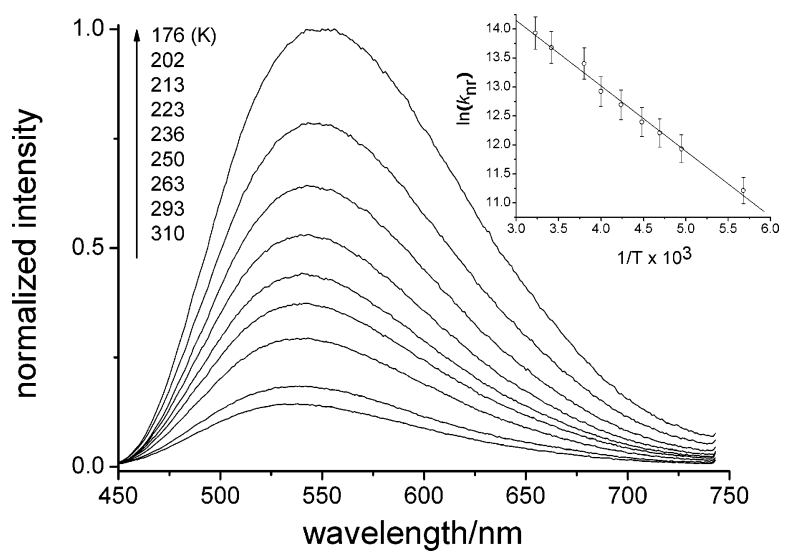

Figure 6. Temperature-dependent emission spectra of complex 3. Insert: Linear graphical plot of $\ln k_{\mathrm{nr}}(T)$ versus $1 / T$ (see text for the definition).

$k_{\mathrm{r}}$ and $k_{\mathrm{nr}}$ represent the radiative decay rate and temperatureindependent radiationless decay rate, respectively, such that the temperature-dependent radiationless decay rate is $k_{\mathrm{nr}}(T)$ $=k_{\mathrm{obs}}-\left(k_{\mathrm{r}}+k_{\mathrm{nr}}\right)$, a plot of $\ln k_{\mathrm{nr}}(T)$ versus $1 / T$ gives a relatively straight line (see insert of Figure 6), and the activation energy $E_{\text {a }}$ for an Arrhenius-type thermally deactivated pathway was deduced to be $\sim 2.3 \mathrm{kcal} / \mathrm{mol}$ in 3 .

It is important to note that during the temperaturedependent study of $\mathbf{3}$, we observed a continuous increase of the emission intensity from 310 to $176 \mathrm{~K}$, in which the emission spectral profile essentially remained unchanged with peak wavelength at $\sim 533-540 \mathrm{~nm}$. Interestingly, however, the spectra underwent a discrete shift to $\sim 490 \mathrm{~nm}$ at $150-$ $77 \mathrm{~K}$ (see Supporting Information for the spectrum obtained at $77 \mathrm{~K}$ ). A similar spectral blue shift was observed for 4 from $553 \mathrm{~nm}$ at $298 \mathrm{~K}$ to $515 \mathrm{~nm}$ at $<150 \mathrm{~K}$ in methylcyclohexane, although the emission intensity only increased by $\sim 2$-fold. The corresponding spectral profile is reminiscent of 3 and 4 in the solid crystal with 475 and $510 \mathrm{~nm}$ peak wavelengths, respectively. Note that $150 \mathrm{~K}$ is close to the freezing point of methylcyclohexane (146 K). Since the emission peak wavelength of $\mathbf{3}$ revealed negligible solvent polarity dependence, the freezing of solvent, hence the slow of the solvent relaxation, i.e., solvatochromism, to account for the spectral shift is not likely. Alternatively, we propose that certain large amplitude motions might have been locked in the solid state as well as in frozen solid solution, such that the electronic configuration alters accordingly. A prime candidate affecting this is the auxiliary phosphine ligand $\mathrm{PPh}_{2} \mathrm{Me}$. We herein tentatively propose that the phenyl torsional motion should affect the donor properties. In solution at $298 \mathrm{~K}$, a relatively free phenyl motion can be executed, such that the electron-donating ability of $\mathrm{PPh}_{2} \mathrm{Me}$ is averaged from these rotational motions. Once in a crystal or in a frozen form at cryogenic temperature, such motions have been restricted, i.e., locked, in a specific angle of plane for the phenyl rings, and the net effect should be quite different from that in solution phase, resulting in a subtle change of the electronic configuration. Nevertheless, one should not eliminate other possibilities, such as the rigidochromic shift ${ }^{27}$ associated with freezing of the solvent as well as the existence of an intramolecular $\pi \pi$ interaction between a phenyl ring and the pyridyl azolate and even certain longrange, intermolecular interactions. For the latter case, an intermolecular ligand-ligand $\pi \pi$ interaction between a ligated chromophore and aryl substituted phosphine ligands has recently been reported in rhenium(I) complexes. ${ }^{28}$

\section{Conclusion}

In conclusion, the triosmium intermediate complexes $\mathrm{OOs}_{3-}$ $\left.(\mathrm{CO})_{8}(\mathrm{fppz})_{2}\right](\mathbf{2 a})$ and $\left[\mathrm{Os}_{3}(\mathrm{CO})_{8}(\mathrm{fptz})_{2}\right](\mathbf{2} \mathbf{b})$ bearing two 2-pyridylazolate ligands have been isolated and characterized to elucidate the reaction mechanism that gives rise to the blue-emitting phosphorescent complexes $\left[\mathrm{Os}(\mathrm{CO})_{2}(\mathrm{fppz})_{2}\right]$ (1a) and $\left[\mathrm{Os}(\mathrm{CO})_{2}(\mathrm{fptz})_{2}\right](\mathbf{1 b})$. For $\mathbf{2 b}$, the reaction with the phosphine ligand $\mathrm{PPh}_{2} \mathrm{Me}$ afforded two hitherto new hydride isomers $\mathbf{3}$ and $\mathbf{4}$, for which the reversible interconversion was clearly established at higher temperatures $(>180$ ${ }^{\circ} \mathrm{C}$ ). The subtle differences in photophysical properties between $\mathbf{3}$ and $\mathbf{4}$ have been attributed to the strong $\pi$-acceptor character of the trans $\mathrm{CO}$ ligand and the interplay of potential energy surfaces between $S_{0}$ and $T_{1}$ states. The results have been further supported by the frontier orbital analyses on the basis of time-dependent density function theory (TDDFT). The results should provide a pertinent fundamental basis for the future design and preparation of highly efficient phosphorescent emitters.

Acknowledgment. This work was funded by the National Science Council of Taiwan, ROC, under Grants NSC 932113-M-007-012 and NSC 93-2752-M-002-002-PAE.

Supporting Information Available: CIF files for complexes $\mathbf{2 b}, \mathbf{3}$, and $\mathbf{4}$ and the calculated energy levels and the associated frontier orbitals of the TDDFT calculation for complexes $\mathbf{3}$ and $\mathbf{4}$. This material is available free of charge via the Internet at http://pubs.acs.org.

IC061301Y

(27) Colombo, M. G.; Hauser, A.; Gudel, H. U. Top. Curr. Chem. 1994, $171,143$.

(28) Tsubaki, H.; Sekine, A.; Ohashi, Y.; Koike, K.; Takeda, H.; Ishitani, O. J. Am. Chem. Soc. 2005, 127, 15544. 